\title{
Laparoscopic Hernia Repair in Pediatrics Population, Evaluation of the IDES technique, A French Multi-Centers Study
}

\author{
Ghazwani Salman $^{1}$, Scalabre Aurelien², Jean-Luc Deluca1, Fakhro Ahmad ${ }^{1}$, John Yao ${ }^{1}$, Gallinet Claire ${ }^{2}$, Vermersch Sophie ${ }^{2}$, \\ Varlet Francois1, Fievet Lucile1*
}

${ }^{1}$ Division of Pediatric Surgery, Avignon Regional Hospital.

${ }^{2}$ Division of Pediatric Surgery Saint Etienne Regional University Hospital, France.

${ }^{3}$ Division of Pediatric Surgery, Jazan University Hospital,Faculty of Medicine, Department of pediatric Surgery,Saudi Arabia

"Corresponding author: Fievet Lucile, Division of Pediatric Surgery, Avignon Regional Hospital, France. Email: Fievet.Lucile@ ch-avignon.fr

Citation: Salman G, Aurelien S, Deluca JL, Ahmad F, Yao J, et al. (2018) Laparoscopic Hernia Repair in Pediatrics Population, Evaluation of the IDES technique, A French Multi-Centers Study. J Surg: JSUR-1151. DOI: 10.29011/2575-9760. 001151

Received Date: 29 June, 2018; Accepted Date: 10 July, 2018; Published Date: 16 July, 2018

\begin{abstract}
Aim of the Study: Recently several laparoscopic techniques have emerged for repair of inguinal hernia in children, the gold standard still being the open herniotomy. This study Evaluates the Inguinal Dissect, Excise and Suture (IDES) technique which includes incision of the peritoneum at the internal ring, dissection of the vas and vessels, excision of the hernia sac and closure of the peritoneal defect.

Methods: This retrospective study includes all consecutive children operated on for inguinal hernia using the laparoscopic IDES technique in 2 centers from December 2015 to December 2017. Clinical data were collected from medical charts.

Main Results: One hundred and fifty-seven (157) patients comprising of 77 females (49.04\%) and 80 males (50.96\%) were involved in the study. The mean age at surgery was 55 months $+/-43$. Asymptomatic contralateral hernias were found in $20 \%$ of cases during laparoscopy and were systematically treated. The mean operating time was 46 min $[21 ; 106]$ for unilateral cases, and $55 \mathrm{~min}$ [27;103] for bilateral cases. No intraoperative complications were reported. Clavinet grade 1 complications occurred in 8 cases, mainly postoperative vomiting. 112 patients under 3 months old were discharged on the same day, and younger patients were usually discharged the next morning. All patients had a follow-up within a 6 weeks period after surgery. No recurrence was observed. In only one case recurrence was suspected but not confirmed during re-do procedure.

Conclusions: Laparoscopic inguinal hernia repair using
\end{abstract}

Keywords: IDES; Laparoscopic Hernia Repair; Paediatric Inguinal Hernia

\section{Introduction}

The commonness of congenital indirect inguinal hernia requiring operative treatment among the paediatric population is at a clinically significant statistical rate of about $1-5 \%$ with between $88-91 \%$ possible occurrences in boys than it occurs in girls [1]. Because of its clinical significance, the treatment of paediatric inguinal hernia has attracted various operative interventions with pain coming out as an important indicator outcome of such procedures. The hernia sac high ligation open herniotomy has been the conventional gold standard operative treatment for paediatric inguinal hernia [2]. However, with advancement in clinical interventions various other approaches in the treatment of inguinal hernia have been developed including the now common laparoscopic treatments are being employed.

\section{Objective}

The aim of this paper is to analyse and present the outcome of paediatric inguinal hernia laparoscopic repair in French Multiple centres using The Dissect, Excise, and Suture (IDES) laparoscopic hernia repair.

\section{Material and Methodology}

Carrying out a retrospective analysis of 2-French medical centres in paediatric laparoscopic hernia repair, the dissect, excise, and suture (IDES) laparoscopic hernia repair technique proposed 
by was adopted Shah, et al. [3]. One hundred and fifty-seven (157) patients comprising of 77 females (49.04\%) and 80 males (50.96\%) were involved in the study. The average age in terms of months for the participants was 55 months. The surgical technique employed on each of the participants involved a general anaesthesia with endotracheal intubation with the subjects held securely and supine while the operation was on course in a manner that while the side containing the hernia was in a higher position, the head was in a lower position. Employing the open technique for $5 \mathrm{~mm} 30^{\circ}$ telescope, a $5 \mathrm{~mm}$ supra-umbilical port was inserted. Pneumoperitoneum was established by $\mathrm{CO}_{2}$ insufflations at pressure of $8 \mathrm{~cm}$ of water and at the rate of 10 per minute. Examination of the affected side and then opposite side was performed to check for the patency of the processes vaginalis. Two more $3 \mathrm{~mm}$ trocars were inserted under laparoscopic guidance at the level of umbilicus in mid-clavicular line on either side as working ports for bilateral hernia. For unilateral hernia, the working port on the side of hernia can be little higher and opposite side little lower, for better triangularisation. In infants and small babies, the working ports were placed little higher than the level of umbilicus. The symptomatic side on the peritoneum at the internal ring was the initial point of incision and involved the proper and careful vas and vessels dissections. Keeping in a mind a targeted dissection length of about $2 \mathrm{~cm}$ in the inguinal canal, the hernial sac was then dissected using scissors. At the internal ring, it was possible to approximate the distance between the inguinal ligament and the conjoint muscle. The closing of the noted peritoneal defect was achieved using a V-Lock 3-0 or Vicryl 4.0 thread introduced the umbilical trocar. Using the body needle and the dissector, the peritoneal bites were removed and later the removal of the hernia sac together with the needle were accomplished after suturing and closing of the peritoneal defect (Figure 1).

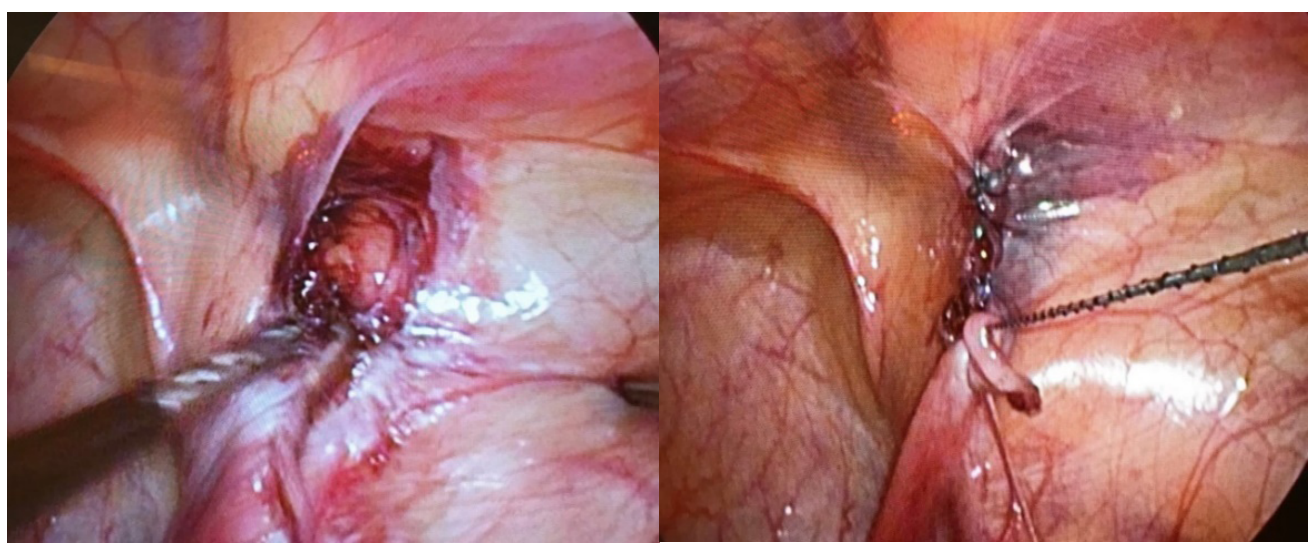

Figure 1: Intra-operative aspect of IDES technique.

\section{Results}

The research involved 157 subjects aged between 0 to 172 months with the average being 55 months. With an average operating time of 43.18 minutes, the highest was 106 minutes with the lowest being 14 minutes. There were few incidences of postoperative complications that included asthmatic crises, gastroenteritis, abdominal pain, vomiting, and wound infection. In addition, there were no recurrences. (Tables 1-3) (Figure 2) indicates the descriptive statistics of the different variables observed in the research process of the study.

\begin{tabular}{|c|c|c|c|c|c|}
\hline Value Label & Value & Frequency & Percent & Valid Percent & Cum Percent \\
\hline & $\mathrm{F}$ & 77 & 49.04 & 49.04 & 50.96 \\
\hline Total & $\mathrm{M}$ & 80 & 50.96 & 100 & 100 \\
\hline
\end{tabular}

Table 1: Sex distribution. 
Citation: Salman G, Aurelien S, Deluca JL, Ahmad F, Yao J, et al. (2018) Laparoscopic Hernia Repair in Pediatrics Population, Evaluation of the IDES technique, A French Multi-Centers Study. J Surg: JSUR-1151. DOI: 10.29011/2575-9760. 001151

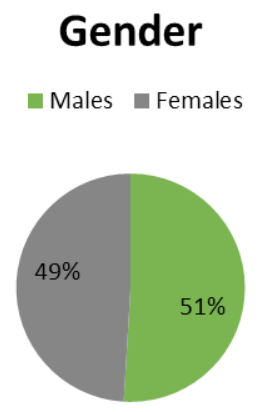

Figure 2: Participants' Gender distribution.

\begin{tabular}{|c|c|c|c|c|c|}
\hline Value Label & Pathology & Frequency & Percent & Valid Percent & Cum Percent \\
\hline & Bilateral & 45 & 28.67 & 28.67 & 28.67 \\
\hline & Bilateral with encysted hydrocele & 1 & 0.64 & 0.64 & 28.66 \\
\hline & Incidental finding of contralateral hernia & 32 & 20.38 & 20.38 & 20.38 \\
\hline & Circumcision and Left Hydrocele and varicocele & 1 & 0.64 & 0.64 & 0.64 \\
\hline & Circumcision & 2 & 1.27 & 1.27 & 2.55 \\
\hline & Intussusceptions & 1 & 0.64 & 0.64 & 3.18 \\
\hline & Left Stephen fowler & 1 & 0.64 & 0.64 & 3.82 \\
\hline & Non & 143 & 91.09 & 91.09 & 94.27 \\
\hline & Right Stephen Fowler & 1 & 0.64 & 0.64 & 94.9 \\
\hline & appendectomy and ovarian cyst excision & 1 & 0.64 & 0.64 & 95.54 \\
\hline & circumcision & 4 & 2.55 & 2.55 & 98.09 \\
\hline & foreskin stretching & 1 & 0.64 & 0.64 & 98.73 \\
\hline & huge & 1 & 0.64 & 0.64 & 99.36 \\
\hline & umbilical hernia & 1 & 0.64 & 0.64 & 100 \\
\hline Total & & 157 & 100 & 100 & \\
\hline
\end{tabular}

Table 2: Concomitant Hernial side and other intraoperative pathologies.

\begin{tabular}{|c|c|c|c|c|c|}
\hline & & Frequency & Percent & Valid Percent & Cum Percent \\
\hline & asthmatic crises & 1 & 0.64 & 0.64 & 0.64 \\
\hline & gastroenteritis & 1 & 0.64 & 0.64 & 1.27 \\
\hline & known patient of diabetes & 1 & 0.64 & 0.64 & 1.91 \\
\hline & $\begin{array}{l}\text { no recurrence on reoperation for recurrence } \\
\text { suspicion }\end{array}$ & 1 & 0.64 & 0.64 & 2.55 \\
\hline & non & 148 & 94.27 & 94.27 & 96.82 \\
\hline & post op abdominal pain & 1 & 0.64 & 0.64 & 97.45 \\
\hline & post op vomiting & 2 & 1.28 & 1.28 & 98.73 \\
\hline & wound infection & 2 & 1.27 & 1.27 & 100 \\
\hline Total & & 157 & 100 & 100 & \\
\hline
\end{tabular}

Table 3: Postoperative course. 


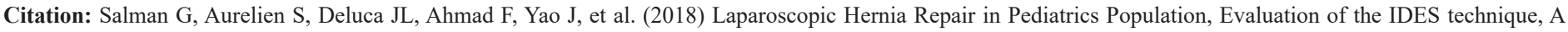
French Multi-Centers Study. J Surg: JSUR-1151. DOI: 10.29011/2575-9760. 001151

\section{Clinical Data Analysis}

The average for hospital stays for each of the subjects in terms of days was 1.36 with the maximum number of days being 7 and the minimum being 1 day. In reference to the operative time, the average for all the subjects was 43.18 with the longest being 106 minutes and the shortest being 14 minutes with a standard deviation of 15.12. Graphically, the analysis of operative time progress can be presented as shown in (Figure 3) below. In the postoperative course 1 case of asthmatic crises, 1 case of gastroenteritis, 1 case of known pt of diabetes, 1 case of abdominal pain, 2 cases of vomiting and 2 cases of wound infection were reported. However, there were no recurrences for all of the subjects. In addition, 142 patients did not experience any postoperative course. In the percentage of concurrent pathology found intra-operative, the details were as observed in table 4 shown above.

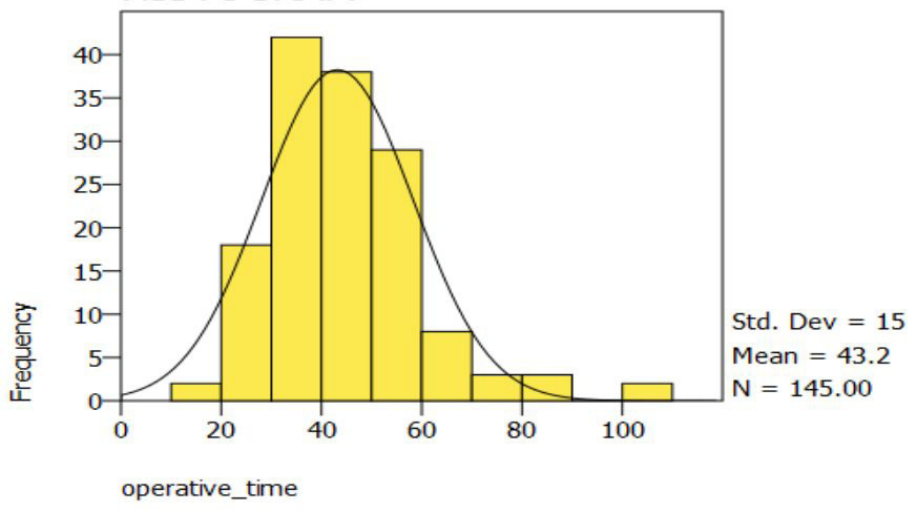

Figure 3: Operative time progress analysis chart.

\section{Discussions}

An inguinal hernia is a common paediatric occurrence that has been for long been treated using the more clinically invasive hernia sac high ligation open herniotomy technique [4]. The open herniotomy technique has been linked to observable recurrences of hernia in patients $[5,6]$. Furthermore, there is a close association of the open herniotomy method with increase postoperative complications [7-9]. However, in the recent years, there has been a course to adopt less invasive approaches and such efforts have included the discovery of surgical techniques such as laparoscopy. In fact, the popularity of the laparoscopic repair of paediatric inguinal hernia is quite high resulting from its consideration not only as a technically easier method due to its ability to improve visualisation of all anatomical structures, prevention of recurrent hernias as well as the possibility of employing a low-cost simulator [10,11]. Other benefits credited to the laparoscopic repair of hernia include minimal dissection and diminished complication rates, significant cosmetic results as well as the repairmen of "contralateral Patent Process Vaginalis (PPV) hernias" [12]. Because of the perceived advantages of the laparoscopic techniques in paediatric hernia repair, its adoption is becoming widespread in many medical facilities. In the treatment of paediatric inguinal hernia, various laparoscopic hernia repair methods have been employed.

For example, in one method an intracorporal knot tying preceded by a purse-string sutured around the patent deep inguinal ring is often prepared for surgical incision ${ }^{11}$. In this study, The Dissect, Excise, and Suture (IDES) laparoscopic hernia repair technique proposed by Shah et al. was adopted. The method involves making an incision, followed by a dissection, removal of the peritoneal bites and the hernia sac after suturing followed by a closing of the peritoneal defect had been done with the incision closed using polyglycolic acid 3-0 [3]. The method does not lead to the impairment of testis $[13,14]$. The use of an absorbable suture is a common practice in laparoscopic hernia repair as was the case in this study. The use of the absorbable suture has also been employed in other studies such Schier [15-18]. However, the adoption of non-absorbable suture can be observed in $[16,19,20]$. From our study, the shortest operative time was 14 minutes. Such duration is also supported by McCormack, et al. who delineate a surgery time of between 14 to 16 minutes [21]. it was apparent that there were no incidences of recurrence. Such findings have also been established by Alzahem who in his adoption of the laparoscopic inguinal hernia repair described a near-zero recurrence rate for paediatric patients of all ages [22]. Incidental finding of hernia in contra-lateral side was observed in $20 \%$ which is significant and repaired at same operation. Concisely, our study supports that the laparoscopic inguinal hernia repair technique is a very efficient method with less complications and rapid recovery.

\section{Conclusion}

From our findings, and discussions, it was apparently clear that laparoscopicinguinalherniarepairisamorecosmeticherniarepairand less painful technique resulting in minimal complication compared to open inguinal hernia repair. Our study also showed that with the adoption of the technique there was no recurrence in our patients.

\section{References}

1. Wolak PK, Patkowski D (2014) Laparoscopic inguinal hernia repair in children using the percutaneous internal ring suturing technique-own experience. Videosurgery and Other Miniinvasive Techniques 9: 53.

2. Abd-Alrazek M, Alsherbiny $\mathrm{H}$, Mahfouz $\mathrm{M}$, Alsamahy $\mathrm{O}$, Shalaby $\mathrm{R}$, et al. (2017) Laparoscopic pediatric inguinal hernia repair: a controlled randomized study. Journal of pediatric surgery 52: 1539-1544.

3. Shah R, Arlikar J, Dhende N (2013) Incise, dissect, excise and suture technique of laparoscopic repair of paediatric male inguinal hernia. Journal of minimal access surgery 9: 72.

4. Bharathi RS, Arora M, Baskaran V (2008) Pediatric inguinal hernia: laparoscopic versus open surgery. JSLS: Journal of the Society of Laparoendoscopic Surgeons 12: 277. 


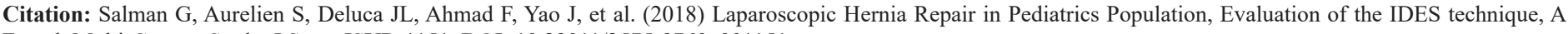
French Multi-Centers Study. J Surg: JSUR-1151. DOI: 10.29011/2575-9760. 001151

5. Yip KF, Tam PKH, Li MKW (2004) Laparoscopic flip-flap hernioplasty: an innovative technique for pediatric hernia surgery. Surgical Endoscopy and Other Interventional Techniques 18: 1126-1129.

6. Niyogi A, Tahim AS, Sherwood WJ, De Caluwe D, Madden NP, et al. (2010) A comparative study examining open inguinal herniotomy with and without hernioscopy to laparoscopic inguinal hernia repair in a pediatric population. Pediatric surgery international 26: 387-392.

7. Schier $F(2006)$ Laparoscopic inguinal hernia repair-a prospective personal series of 542 children. Journal of pediatric surgery 41: 10811084.

8. Turial S, Enders J, Krause K, Schier F (2011) Laparoscopic inguinal herniorrhaphy in babies weighing $5 \mathrm{~kg}$ or less. Surgical Endoscopy 25: $72-78$.

9. Tsai YC, Wu CC, Ho CH, Tai HC, Wu CC, et al. (2011) Minilaparoscopic herniorrhaphy in pediatric inguinal hernia: a durable alternative treatment to standard herniotomy. Journal of pediatric surgery 46 : 708-712.

10. Parelkar SV, Oak S, Gupta R, Sanghvi B, Shimoga PH, et al. (2010) Laparoscopic inguinal hernia repair in the pediatric age group-experience with 437 children. Journal of pediatric surgery 45: 789-792.

11. Jaffer U, Manoharan S, Tsang T (2009) Low-cost laparoscopic paediatric inguinal hernia repair simulator. The Annals of The Royal College of Surgeons of England 91: 515-515.

12. Shalaby R, Ibrahem R, Shahin M, Yehya A, Abdalrazek M, et al. (2012) Laparoscopic hernia repair versus open herniotomy in children: a controlled randomized study. Minimally invasive surgery 2012: 8.

13. Chan KL, Chan HY, Tam PKH (2007) Towards a near-zero recurrence rate in laparoscopic inguinal hernia repair for pediatric patients of all ages. J Pediatr Surg 42: 1993-1997.
14. Schier F, Turial S, Hückstädt T, Klein KU, Wannik T (2008) Laparoscopic inguinal hernia repair does not impair testicular perfusion. Journal of pediatric surgery 43 : 131-135.

15. Schier F, Montupet $P$, Esposito $C$ (2002) Laparoscopic inguinal herniorrhaphy in children: a three-centre experience with 933 repairs. Journal of pediatric surgery 37 : 395-397.

16. Higa KD, Ho T, Boone KB (2003) Internal hernias after laparoscopic Roux-en-Y gastric bypass: incidence, treatment and prevention. Obesity surgery 13: 350-354.

17. Oak SN, Parelkar SV, Ravikiran K, Pathak R, Viswanath N, et al. (2007) Large inguinal hernias in infants: Is laparoscopy the answer? J Laparoendosc Adv Surg Tech A 17: 114-118.

18. LeBlanc KA (2007) Laparoscopic incisional hernia repair: are transfascial sutures necessary? A review of the literature. Surgical Endoscopy 21: $508-513$

19. Barbaros U, Asoglu O, Seven R, Erbil Y, Dinccag A, et al. (2007) The comparison of laparoscopic and open ventral hernia repairs: a prospective randomized study. Hernia 11: 51-56.

20. Wassenaar E, Schoenmaeckers E, Raymakers J, van der Palen J, Rakic S (2010) Mesh-fixation method and pain and quality of life after laparoscopic ventral or incisional hernia repair: a randomized trial of three fixation techniques. Surgical Endoscopy 24: 1296-1302.

21. McCormack K, Scott N, Go PM, Ross SJ, Grant A (2003) Laparoscopic techniques versus open techniques for inguinal hernia repair. The Cochrane Library 2003.

22. Alzahem A (2011) Laparoscopic versus open inguinal herniotomy in infants and children: a meta-analysis. Pediatric surgery international 27: 605-612. 